\title{
Experiencias actuales de los bancos del agua en España. Estudio de los casos del G uadiana, Guadalquivir, Júcar y Segura ${ }^{1}$
}

\author{
Teresa M aría Navarro Caballero \\ Profesora de Derecho Administrativo \\ Universidad de Murcia
}

\begin{abstract}
SUMARIO: I. INTRODUGGIÓN. II. ANÁLISIS DE LOS GENTROS DE INTERCAMBIO DE DEREGHOS AL USO DEL AGUA CONSTITUIDOS EN LA ACTUALIDAD. A) Confederación Hidrográfica del Segura. B) Confederación Hidrográfica del Guadiana. 1. El contexto normativo: el Plan Especial del Alto Guadiana. 2. La degradación del alto Guadiana como causa determinante del PEAG. 3. Primeras actuaciones normativas sobre la zona de influencia del $P E A G$ como exponentes de la nueva política pública medioambiental. 4. El Plan especial del alto Guadiana: breve referencia a sus antecedentes, contenido y programas de medidas. Consideración especial de los centros de intercambio de derechos objeto de estudio. C) Confederación Hidrográfica del Júcar. D) Confederación Hidrográfica del Guadalquivir. III. FINAL
\end{abstract}

\section{RESUMEN:}

Los centros de intercambio de derechos al uso del agua constituyen uno de los instrumentos más novedosos de entre todos los recogidos en el TRLA que tienden a la redistribución de los recursos hídricos, con la finalidad de optimizar socialmente su uso. Precisamente por tal circunstancia se han convertido en uno de los retos del actual Derecho de aguas español al representar un medio útil que, en conjunción con otros instrumentos de gestión del Dominio Publico Hidráulico, permite afrontar la delicada situación hidrológica que desde hace años atraviesa nuestro país. A mayor abundamiento, el Real Decre-

\footnotetext{
${ }^{1}$ Este trabajo constituye una versión adaptada de la memoria del Proyecto de Investigación "Los bancos del Agua en España. Análisis de las experiencias actuales y propuestas de futuro", desarrollado en el marco del Convenio específico de colaboración entre la Universidad de Murcia la Fundación Instituto Euromediterráneo del Agua para la realización de actividades conjuntas de investigación en recursos hídricos, firmado el 21 de noviembre de 2008.
} 
to-Ley 9/2006, de 15 de septiembre, por el que se adoptaban medidas urgentes para paliar los efectos de la sequía en las poblaciones y explotaciones agrarias de regadío de determinadas cuencas hidrográficas reforzó la eficacia de estos centros de intercambio con la finalidad de que este instrumento sirviera para dar respuesta a objetivos medioambientales o de interés de la Comunidad Autónoma, línea que fue seguida por los posteriores decretos de sequía. En virtud del Acuerdo del Consejo de Ministros de 15 de octubre de 2004 se aprobó la constitución de los mencionados centros de intercambio en las cuencas del Segura, Júcar y Guadiana. Posteriormente, el 4 de abril de 2008, el Consejo de Ministros adoptó el acuerdo por el que se autorizaba la constitución de un centro de intercambio en la cuenca del Guadalquivir. En el presente trabajo se efectúa un estudio y seguimiento del funcionamiento de los centros de intercambio en las cuatro cuencas hidrográficas en que se han constituido que permita concretar el alcance de su efectividad como instrumento de redistribución y de optimización social de caudales, de reordenación de los aprovechamientos y de la racionalización de su utilización.

Palabras clave:

Derecho de Aguas, bancos de agua, confederaciones hidrográficas, ofertas públicas de adquisición de derechos al agua

\section{ABSTRACT:}

"Centros de intercambio" of rights to the exclusive use ofe water are a new are a new instrument in TRLA which redistribute water resources to optimize socially the use of water. They are a challenge of actual Spanish Water Law because they fight the actual drougt. Indeed, the Real Decreto.Ley 9/2006, 15 septiembre, increased the "centros de intercambio" to respond environmental objectives. The present work analyzes the operation of "centros de intercambio" in the Guadiana, Guadalquivir, Júcar and Segura basins to know water markets effectiveness in Spain.

Key words:

Water Law, water market, Confederations Basins, water comunity

\section{INTRODUCAIÓN}

Los centros de intercambio de derechos al uso del agua se crearon en el Derecho de aguas español, junto con el contrato de cesión, como uno de los instrumentos más novedosos de entre todos los recogidos en el TRLA que tienden a la redistribución de los recursos hídricos, con la finalidad de optimizar 
socialmente su uso. Precisamente por tal circunstancia desde su origen se convirtieron en uno de los retos del actual Derecho de aguas español al representar un medio útil que, en conjunción con otros instrumentos de gestión del Dominio Publico Hidráulico, permite afrontar la dramática situación hidrológica que desde hace años atraviesa nuestro país. En efecto, la necesidad de afrontar la situación de déficit hídrico que en algunas cuencas hidrográficas no era sólo coyuntural sino, antes al contrario, estructural requería adoptar una política hidráulica que combinara los tradicionales instrumentos de gestión de los recursos hídricos con los más modernos, como los bancos del agua. Éstos se convirtieron, así, en la alternativa al tradicional y rígido régimen concesional por presentar atractivos suficientes que aseguren la colaboración del concesionario, de gran trascendencia para la efectividad de su funcionamiento.

Esta figura está recibiendo un progresivo acogimiento por parte de la doctrina y Administración hídrica. De tal forma, una de las conclusiones del Seminario de Regiones Mediterráneas sobre la Visión Europea del Agua, celebrado en Castellón en 2008, y que se convirtió en la posición europea en el V Foro Mundial del Agua declaraba que los comúnmente denominados bancos de agua constituían un sistema que permitía una mejor apreciación del valor del recurso.

Pese a la importancia que para la reasignación de recursos hídricos tienen, los centros de intercambio de derechos al uso del agua se han configurado en el Derecho de aguas español con un marcado carácter excepcional, lo que se manifiesta, de un lado, porque su creación única y exclusivamente procede previo Acuerdo del Consejo de Ministros, a propuesta del Ministro de Medio Ambiente y, del otro, por las limitadas y singulares situaciones en que aquélla tendrá lugar. En efecto, la constitución de los centros de intercambio de derechos al uso del agua ha sido relegada por el legislador para situaciones particulares y de mayor gravedad que aquellos supuestos en que procederán los contratos de cesión. En virtud del artículo 71.1 del TRLA y 354.1 del RDPH, estas situaciones son las de falta de disponibilidad de recursos que obligue al Organismo de cuenca a fijar la explotación de los mismos para garantizar su uso racional (artículo 55); los casos de declaración de sobreexplotación de acuíferos (artículo 56); los supuestos de sequías extraordinarias, estados de necesidad, urgencia o concurrencia de situaciones anómalas o excepcionales (artículo 58); y, en fin, aquellos otros que reglamentariamente se determinen por concurrir situaciones análogas. Además, se permite a las Comunidades Autónomas instar a los Organismos de cuenca para realizar adquisiciones de derechos de uso del agua para atender fines de interés autonómico. 
El elemento subjetivo de los centros de intercambio se integra, de un lado, de la Administración hidráulica que efectúa las ofertas públicas de adquisición y cesión de derechos y, del otro, de los usuarios que podrán concurrir a las mismas. Son, sin duda, estos últimos los que plantean mayores interrogantes en la medida en que su definición no ha quedado claramente establecida en el TRLA ni en el RDPH, por lo que resulta de gran interés el conocimiento de las experiencias existentes en nuestro país. Debido a la finalidad de redistribución de caudales que es innata a los centros de intercambio, sólo podrán ceder sus derechos los concesionarios o titulares de aprovechamientos al uso privativo de las aguas que los tengan inscritos en el Registro de Aguas o en el catálogo de aprovechamientos de la cuenca. Éstos, en las solicitudes que dirijan al Organismo de cuenca con tal fin, deberán identificar el concesionario o titular que desea ceder sus derechos; el título jurídico que ampara el derecho al uso privativo de las aguas que ostenta el solicitante; el volumen de agua que está dispuesto a ceder; así como justificar el cumplimiento del resto de los requisitos fijados por el Organismo de cuenca para poder acudir a la oferta pública de adquisición, en especial los referentes a la calidad del recurso y a los criterios relativos al retorno de las aguas susceptibles de cesión.

De otro lado, el elemento objetivo de los centros de intercambio lo constituyen los derechos al uso privativo de las aguas que puedan ser objeto de intercambio porque reúnan los requisitos determinados en las ofertas públicas de adquisición y eventual cesión. En efecto, en aquéllas se determinarán no sólo las características de los aprovechamientos que puedan ceder o adquirir derechos sino también los requisitos técnicos de los recursos, en especial, los referentes a la calidad y al retorno de las aguas objeto de cesión. De igual modo, las ofertas públicas concretarán los criterios en cuya virtud el Organismo de cuenca seleccionará los derechos objeto de adquisición y aquéllos que resulten adjudicatarios de los mismos en la posterior cesión. De igual modo, integra el elemento objetivo el precio fijado por el Organismo de cuenca que reciban o abonen las partes por ceder o adquirir respectivamente los derechos en cuestión. Concretamente, los importes máximos y mínimos de la compensación económica así como las condiciones y formas de pago vendrán fijados en las ofertas públicas que realice el Organismo de cuenca, que habrá de tener en cuenta un porcentaje no superior al cinco por ciento en concepto de gastos de gestión.

El intercambio de los derechos se articula en dos fases distintas. En primer lugar, el Organismo de cuenca procede a la captación de derechos de uso del agua a través de las correspondientes ofertas públicas de adquisición de derechos, dirigidas a los concesionarios que reúnan las características detalladas en las mismas. En segundo término, se efectuará la posterior cesión de los dere- 
chos adquiridos a aquellos usuarios que acepten las condiciones y precios ofertados por el Organismo de cuenca. Además, tanto las adquisiciones como las enajenaciones (cesiones) posteriores del derecho al uso del agua, deberán respetar los principios de publicidad y libre concurrencia, así como llevarse a cabo conforme al procedimiento y criterios de selección que se determinen reglamentariamente.

La puesta en marcha de los centros de intercambio de derechos al uso del agua requiere que el Consejo de Ministros, a propuesta del Ministro de Medio Ambiente, adopte un Acuerdo por el que apruebe la constitución de los mismos y faculte al Organismo de cuenca para realizar las ofertas públicas de adquisición de derechos, hecho que para los bancos del agua objeto de estudio tuvo lugar en 2004 y 2008.

La intervención administrativa en los centros de intercambio de derechos al uso del agua puede decirse que es plena. En efecto, la Administración se erige en la verdadera artífice de todo el procedimiento del intercambio. Pues, en primer lugar, la autoridad medioambiental solicita la constitución del centro de intercambio y, una vez aprobada por el Gobierno, será la Administración hidráulica la que dirigirá el proceso. Su intervención es total al concretar en todos sus extremos la oferta pública de adquisición de derechos y, posteriormente, hacer lo propio con la oferta pública de cesión de los mismos. Como consecuencia de esta activa participación pública, éstos se admiten abiertamente por quienes que muestran reticencias al contrato de cesión de derechos al uso privativo de las aguas. En efecto, en este caso la Administración hídrica tiene un papel mucho más significativo que el de la mera intermediación entre las partes interesadas en adquirir o ceder caudales, pues en los centros de intercambio la Administración hídrica actúa como algo más que un intermediario ya que ella misma es quien determina la posibilidad de transacciones y su última finalidad. En coherencia con todo lo anterior se conciben los centros como un mecanismo de intercambio de caudales en el espacio y en el tiempo que están gestionados, supervisados y ordenados por la propia Administración, por lo se ha dicho que ningún otro mecanismo de mercado podría contar con más garantías de equidad, información pública y de respeto a la Ley**

De la regulación legal y reglamentaria de los centros de intercambio expuesta se desprende que el legislador sólo ha tomado en consideración la pri-

\footnotetext{
* GARRRIDO COLMENERO, A., "Consideraciones económicas sobre los mercados de agua”, en La reforma de la Ley de Aguas, EMBID IRUJO, A. (dir), Cívitas, Madred, 200, p. 515.
} 
mera parte del proceso - la oferta pública de adquisición de caudales- sometiendo a una total ausencia de regulación la segunda parte del mismo -la posterior cesión de los caudales adquiridos-. Este es uno de los extremos en los que el conocimiento de la realidad resultaría de gran importancia, al permitir analizar y comparar cómo se ha articulado esta fase del procedimiento carente de regulación en las Confederaciones Hidrográficas objeto de estudio. Sin embargo, la práctica ha demostrado que esta segunda fase no ha tenido lugar hasta la fecha, ya que las ofertas se han limitado a la adquisición de derechos para su posterior destino a fines ambientales, como la conservación o mantenimiento de los caudales ecológicos ${ }^{2}$.

\section{ANÁLISIS DE LOS GENTROS DE INTERGAMBIO DE DERE- CHOS AL USO DEL AGUA CONSTITUIDOS EN LA AGTUA- LIDAD}

La constitución de los centros de intercambio en las cuencas hidrográficas españolas ha requerido bastantes años - desde su creación por Ley 46/1999, de modificación de la Ley de Aguas de 1985- hasta su consumación en determinados Organismos de cuenca. Pese a que su creación es muy anterior, el Programa A.G.U.A. (Actuaciones para la Gestión y Utilización del Agua) del Ministerio de Medio Ambiente hace suyos los bancos del agua al considerarlos acordes con los principios asumidos por aquél. En efecto, el Programa A.G.U.A. previó la creación de un Banco Público del Agua en cada cuenca hidrográfica, como instrumento para reasignar los derechos históricos al agua con criterios de equidad, eficiencia y sostenibilidad, corrigiendo el déficit hídrico de las cuencas hidrográficas en que se constituyan y facilitando la consecución de un estado ecológico adecuado de sus aguas superficiales y subterráneas. Como se verá, finalmente solo se han constituido en las confederaciones más castigadas por la escasez de agua.

En virtud del Acuerdo del Consejo de Ministros de 15 de octubre de 2004 se aprobó la constitución de los mencionados centros de intercambio en las cuencas del Segura, Júcar y Guadiana, sin embargo los Acuerdos de las Juntas

\footnotetext{
${ }^{2}$ Un estudio más detallado del régimen jurídico de este instrumento de reasignación puede verse en NAVARRO GABALLERO, T. M., Los instrumentos de gestión del Dominio público hidráulico, Tirant lo Blanch, Valencia, 2007, y NAVARRO CABALLERO, T. M., "Los centros de intercambio de derechos al uso privativo de las aguas. Perspectivas actuales y retos de futuro", Retos del Derecho en el siglo XXI, GARCÍA COSTA y PARDO LÓPEZ, Tirant lo Blanch, Valencia, 2009, pp. 361-379.
} 
de Gobierno de las respectivas Confederaciones no recayeron hasta el 15 de diciembre de 2006, 27 de febrero de 2007 y 4 de septiembre de 2007. Particularmente, en el caso de la cuenca del Guadiana el primer banco del agua se autorizó por un importe nada desdeñable de treinta millones de euros y reviste una gran trascendencia al constituirse como el principal instrumento diseñado en el Plan Especial del Alto Guadiana, junto con el contrato de cesión, con el que afrontar la sobreexplotación de los acuíferos de la misma. De igual modo, el Real Decreto-Ley 9/2006, de 15 de septiembre, por el que se adoptan medidas urgentes para paliar los efectos de la sequía en las poblaciones y explotaciones agrarias de regadío de determinadas cuencas hidrográficas reforzó la eficacia de estos centros de intercambio con la finalidad de que este instrumento sirviera para dar respuesta a objetivos medioambientales o de interés de la Comunidad Autónoma. El reciente Real Decreto-Ley 14/2009, de 4 de diciembre, por el que se adoptan medidas urgentes para paliar los efectos producidos por la sequía en determinadas cuencas hidrográficas, ha seguido en esta dirección.

Más recientemente, el 4 de abril de 2008, el Consejo de Ministros ha adoptado el acuerdo por el que se autoriza la constitución de un centro de intercambio en la cuenca del Guadalquivir con la declarada intención de acometer una explotación más racional de los recursos hídricos y obtener así una mayor disponibilidad de los mismos, al tiempo de introducir nuevas formas de gestión del agua y una amplia concienciación de la sociedad en relación con las necesidades reales de agua y la mejor utilización de estos recursos.

En todos los casos son pues objetivos declarados de los centros de intercambio la reordenación de una parte importante de los recursos hídricos para aplicar los criterios de equidad, eficiencia y sostenibilidad así como corregir el déficit hídrico en estas Cuencas Hidrográficas, facilitando la consecución de un estado ecológico adecuado de sus aguas tanto superficiales como subterráneas.

Si bien ésta es la situación actual conviene no olvidar que las Confederaciones Hidrográficas se declaraban abiertamente incapaces de afrontar -en el corto plazo de tiempo que para que fuera efectivo requería el intercambio de caudales- un expediente de estas características, por lo que resulta de un elevado interés comprobar cómo están teniendo lugar finalmente los intercambios referidos a través de la experiencia de los citados Organismos de cuenca.

\section{A) CONFEDERAGIÓN HIDROGRÁFIGA DEL SEGURA}

En la CHS se han realizado hasta la fecha dos ofertas públicas de adquisición de derechos. La primera fue aprobada por Acuerdo de la Junta de Go- 
bierno de la citada Confederación de 27 de febrero de 2007 y contaba con un presupuesto de licitación de 700.000 euros. En ella, resulta interesante destacar cómo de entre los diversos destinos que pudieran haberse dado a los caudales adquiridos la oferta nació con la declarada intención de destinarlos a contribuir al mantenimiento de los caudales medioambientales de los ríos Segura y Mundo así como a mejorar la garantía de los abastecimientos a población. En efecto, la sequía que a la sazón azotaba a la citada cuenca hacía previsible que en el año hidrológico en curso fuera preciso establecer limitaciones de aprovechamientos del orden, como mínimo, del 50\% de los respectivos volúmenes inscritos o concesionales lo que conllevaría la consiguiente reducción de los equivalentes volúmenes ambientales circulantes por los cauces de la cuenca, afectando también previsiblemente al normal abastecimiento a población.

Para tal fin se han realizado en esta cuenca dos ofertas públicas de adquisición de derechos (en adelante OPAD) en los años 2007 y 2008. Como se ha indicado, la oferta 01/07 fue aprobada por Acuerdo de la Junta de Gobierno de la Confederación Hidrográfica del Segura en su sesión de 27 de febrero de 2007 y publicada en el BOE el 5 de abril del mismo año. La segunda oferta, la 01/2008, fue aprobada por la Comisión Permanente de la Junta de Gobierno de 7 de noviembre de 2007 y publicada en el BOE el 23 de febrero de 2008. En ambos casos, la oferta pública tenía por objeto la enajenación por parte de sus titulares y la consiguiente adquisición por la CHS de los derechos que reunieran las condiciones que más adelante se detallarán. Lo significativo que ha de resaltarse en este momento es que, a diferencia de lo que sucede en otras cuencas, la enajenación tuvo carácter temporal por estar referida al año hidrológico 2007/2008, lo que planteó un problema práctico añadido ante la dificultad de concluir el procedimiento adquisitivo antes del comienzo de la campaña de riego, como habrá ocasión de comprobar. Los destinatarios de la OPAD fueron los concesionarios y titulares de aprovechamientos de carácter consuntivo cuyos derechos estuvieran inscritos en las Secciones A o C del Registro de Aguas o se encontraran en trámite de regularización con informe favorable del Servicio instructor. La cesión se refería a la totalidad del porcentaje de sus derechos que les correspondiera para el total del año hidrológico y una vez deducidos aquellas cantidades que hubieran consumido en el momento de suscribir el contrato. Sin embargo, ésta, que a priori parecía una exigencia lógica, tuvo una difícil aplicación en la práctica puesto que el proceso adquisitivo finalizó una vez comenzada la campaña de riego, momento en el que muchos de los cedentes habían hecho uso de su derecho al riego con la consiguiente disminución del caudal a ceder, provocando reticencia e incluso reclamaciones por parte de éstos ante la 
corrección cuantitativa impuesta por la Confederación de los caudales finalmente objeto de adquisición.

De entre los requisitos impuestos en la OPAD a los aprovechamientos susceptibles de cesión cabe destacar la exigencia común en la mayoría de las experiencias de otras cuencas, de que aquéllos hubieran sido utilizados en al menos una de las campañas 2003/2004, 2004/2005, 2005/2006, 2006/2007. Es preciso resaltar que esta exigencia que se encamina a garantizar que los volúmenes objeto de la cesión fueran reales y, por lo tanto, efectivamente disponibles puede resultar un tanto laxa. Dado que el RDPH no establece ninguna exigencia al respecto para los centros de intercambio, hubiera sido recomendable haber seguido las exigencias más rigurosas impuestas para fijar el volumen objeto de la cesión en los supuestos del contrato de cesión. En efecto, el artículo 345 del RDPH exige para dicho cálculo que se tengan en cuenta los valores del volumen realmente utilizado durante los cinco últimos años, valor que se podrá corregir en función de la dotación objetivo que fije el plan hidrológico de la cuenca, los retornos que procedan, las circunstancias hidrológicas extremas y el respeto a los caudales medioambientales establecidos o, en su caso, al buen uso del agua. En todo caso, para la determinación del volumen ofertable (el total real aprovechable a que tenga derecho el ofertante en el momento en que sea aceptada su oferta) se tendrían en cuenta las limitaciones que fueran establecidas o se consideraran previsibles para ese aprovechamiento por el Organismo de cuenca en el año hidrológico en curso.

Por otro lado, excepcionalmente se permitió ofertar una cantidad inferior al total neto aprovechable manteniendo el aprovechamiento en explotación si se justificaba debidamente que ambos usos eran compatibles, siempre que fuera posible medir separadamente las cantidades dedicadas a cada uso. Sin embargo, es necesario constatar que esta posibilidad no fue finalmente utilizada por ningún cedente.

La selección de los aprovechamientos se realizó priorizando las ofertas por razón, de un lado, de la ubicación de la explotación y menor influencia ambiental sobre los caudales y, del otro, por el menor precio de la misma. El importe máximo de la compensación económica se estableció en $0,18 €$ por metro cúbico. En el caso de que el aprovechamiento de los caudales por la Administración exigiera consumos eléctricos éstos serían abonados separadamente, estando el concesionario obligado a permitir el uso de sus instalaciones a tal efecto.

En la práctica, las experiencias de la cuenca del Segura han tenido, sin embargo, poca efectividad por diversas circunstancias. De un lado, la fal- 
ta de previsión anticipada de la fecha de realización de la ofertas provocó que éstas concluyeran una vez iniciadas las campañas de riego. Sin duda, esta circunstancia hace aconsejable bien una mayor anticipación para futuras convocatorias, bien establecer el dies ad quem para la presentación de las solicitudes por los interesados no desde la fecha de publicación en el BOE, como hasta ahora, sino desde la fecha de publicación en los diarios oficiales de las Comunidades Autónomas implicadas, ante el menor retraso que éstos llevan respecto a las publicaciones del BOE. Por otro lado, cuantitativamente el volumen objeto de estos bancos no resulta significativo puesto que en la práctica no alcanza el 1\% de los recursos manejados por la Confederación, lo que tal vez puede deberse al tipo de cultivo predominante en la cuenca. En efecto, el cultivo leñoso, en especial los cítri$\cos$, que se deje de regar durante un año requiere para su recuperación al menos cuatro años más por lo que parece recomendable que las adquisiciones se dirijan a otro tipo de cultivo (no leñoso) teniendo como destinatario este último.

\section{B) CONFEDERAGIÓN HIDROGRÁFIGA DEL GUADIANA}

\section{EL CONTEXTO NORMATIVO: EL PLAN ESPECIAL DEL ALTO GUADIANA}

La Confederación Hidrográfica del Guadiana goza de una experiencia más dilatada respecto a la convocatoria de ofertas públicas de adquisición de derechos al uso del agua. En efecto, la primera tuvo lugar por Resolución de la Presidencia de la Confederación de 25 de octubre de 2006 y fue publicada en el BOE el 11 de noviembre del mismo año. Posteriormente han tenido lugar otras tres ofertas, dos en el año 2007, una en 2008 y las más recientes de 2009. Los importes de dichas ofertas han ido aumentando cuantitativamente, desde los $600.000 €$ de la $1 / 06,10.000 .000 €$ la $1 / 07,30.000 .000 €$ la 2/07, 10.301.724,14€ la 1/08 o los más elevados de las últimas convocatorias de 2009 que ascendieron a $20.000 €$ y $11.950 €$.

La mayor importancia cuantitativa que las ofertas públicas de adquisición de derechos tienen en el ámbito de esta cuenca obedece al hecho de que aquéllas constituyen un instrumento de gran relevancia en el Plan Especial del Alto Guadiana (en adelante PEAG) aprobado por Real Decreto 13/2008, de 11 de enero. Es bien sabida la compleja problemática medioambiental a que se encuentra sometida la Cuenca Alta del Guadiana y que trata de afrontarse y remediarse a través del citado Plan. En efecto, la reordenación de los derechos de uso de aguas mencionada en la disposición adicional cuarta de la Ley 
10/2001, de 5 de julio, del Plan Hidrológico Nacional tiene la finalidad declarada de propiciar la recuperación hídrica de las masas de agua subterránea así como la de mejorar el estado de las aguas superficiales asociadas a aquéllas. Pero antes de adentrarnos en el conjunto de medidas incorporadas al PEAG conviene abundar un tanto en la situación ambiental que ha llevado al mismo

Con fecha de 11 de enero de 2008 se aprueba el Plan Especial del Alto Guadiana en virtud de Real Decreto 13/20083 , cuya previsión legal encuentra justificación, como puede leerse en su preámbulo, en una situación ambientalmente muy degradada en este lugar como consecuencia de un conjunto de causas que interrelacionadas han conducido de forma progresiva a una amenaza importante para esta zona del territorio nacional ${ }^{4}$. Con amparo en la disposición adicional cuarta de la Ley 10/2001, del Plan Hidrológico Nacional $^{5}$, el PEAG se presenta como un acicate más para la necesaria instauración de una nueva política que, en plena integración con los objetivos medioambientales de la Directiva 2000/60/CE en relación con las aguas subterráneas ${ }^{6}$, afronte decididamente las causas del problema de la zona, establecien-

${ }^{3}$ Su publicación tuvo lugar en el BOE de 24 de enero de 2008.

${ }^{4}$ Como advierte DELGADO PIQUERAS, un conjunto de factores tecnológicos, económicos y sociológicos dio lugar en La Mancha a una explotación acelerada de los recursos hídricos subterráneos. Así mismo, la falta de previsión legislativa permitió un desordenado aprovechamiento agrícola que transformó ingentes extensiones de cultivos tradicionales de secano en modernas fincas de regadío, hecho que, junto a un clima no demasiado favorable, derivó en una negativa repercusión sobre los ecosistemas húmedos. En tal sentido, advierte el autor cómo hasta los años setenta las actuaciones de transformación agrícola hicieron desaparecer tres cuartas partes de las veinticincomil hectáreas que se calcula ocupaban los humedales en esta región. La mayoría de los que perduran son pequeñas lagunas de origen endorreico junto con los dos humedales más emblemáticos, las Tablas de Daimiel y las Lagunas de Ruidera (Delgado PiQueras, F., Derecho de aguas y medio ambiente, Tecnos, Madrid, 1992, p. 301).

${ }^{5}$ Ciertamente, la disposición adicional cuarta de la Ley del Plan Hidrológico Nacional ordena llevar a cabo una serie de actuaciones tendentes a mantener un uso sostenible de los acuíferos de la cuenca alta del Guadiana tales como la reordenación de los derechos de uso del agua, tendente a la recuperación ambiental de los acuíferos; la autorización de modificaciones en el régimen de explotación de los pozos existentes; la concesión de aguas subterráneas en situaciones de sequía o, en fin, cualesquiera otras medidas que pretendan el equilibrio hídrico y ambiental permanente de la citada cuenca.

${ }^{6}$ En efecto, el artículo 4.1.b) ii) obliga a los Estados miembros en un plazo de quince años prorrogables en función del estado de las masas de aguas de que se trate, a proteger, mejorar y rege- 
do un modo de actuación que conduzca a una progresiva y permanente mejora de la situación ambiental, propiciando un horizonte económicamente consolidado y sostenible de la actividad agrícola y económica en el territorio ${ }^{7}$.

Por otro lado, el ámbito territorial de aplicación del PEAG es la cuenca del río Guadiana, aguas arriba de la desembocadura del río Jabalón, incluyendo la cuenca de éste. Esto es, la cuenca alta del Guadiana que, con una extensión de $18.900 \mathrm{~km}^{2}$, comprende la cabecera y cuenca alta del río, limitando al noroeste con la Sierra de Altamira, al norte y oeste con los Montes de Toledo y al sur con el Campo de Montiel, que constituye el origen del Guadiana en su río Pinilla. En el centro de la cuenca alta se ubica la Llanura Manchega, el elemento más característico de todo el territorio por su permeabilidad, y donde se encuentran los Ojos y las Tablas de Daimiel, rebosadero natural del acuífero 23. Como afirma el PEAG al describir la zona a la que afecta, el Alto Guadiana se caracteriza hidrológicamente por una destacable interacción entre las aguas superficiales y las subterráneas, debido a la abundancia de formaciones geológicas permeables, principalmente calcáreas, y a su relieve poco accidentado. Estas condiciones propiciaron una de las principales singularidades de esta zona semiárida como es la presencia de numerosos humedales - existen más de cien humedales en la Cuenca Alta del Guadiana- que sirven como reservas de biodiversidad y hábitats de una importante fauna y flora, además de contribuir, por las comunidades vegetales que llevan asociadas, a la retención de sedimentos y nutrientes de los suelos.

El Plan Especial del Alto Guadiana ha provocado valoraciones y expectativas encontradas, concibiéndose tan pronto como la vía de solución definitiva a medio y largo plazo (2015-2027) que permitirá alcanzar definitivamente un desarrollo sostenible en la zona de afección (en virtud de la reconversión de la

nerar todas las masas de agua subterránea así como garantizar un equilibrio entre la extracción y la alimentación de dichas aguas para alcanzar un buen estado de las aguas subterráneas. En armonía con tal dictado y, consecuentemente con la disposición adicional undécima 1. a) del TRLA, el PEAG tiene una vigencia temporal inicialmente limitada hasta el 31 de diciembre de 2015 aunque, si una vez transcurrido dicho término no se han alcanzado los objetivos de buen estado, lo que por otra parte parece previsible, podrán prorrogarse - eso sí, mediante real decreto del Gobierno de la Nación previo acuerdo con la Junta de Comunidades de Castilla-La Mancha- todas o algunas de sus medidas conforme a lo establecido en la mencionada disposición adicional del TRLA.

${ }^{7}$ Preámbulo del Real Decreto 13/2008, de 11 de enero, por el que se aprueba el Plan Especial del Alto Guadiana. 
economía agraria y rural que las medidas de gestión, restricción y control de la demanda terminarán produciendo), como el instrumento a través del cual se llevará a la desertificación a la Mancha Húmeda, por asumir consumos muy superiores a los que permitiría la recuperación ambiental de la zona ${ }^{8}$.

\section{LA DEGRADAGIÓN DEL ALTO GUADIANA COMO GAUSA DE- TERMINANTE DEL PEAG}

La consabida degradación de esta zona fue consecuencia de diversas acciones de tipo antropológico que originaron impactos en la zona y que han dado lugar a la misma. Así, el cambio de usos del suelo en virtud de la desecación de los humedales, la importante reducción de la superficie forestal que apenas ocupa un $15 \%{ }^{9}$, el aumento de la superficie cultivada y de la actividad urbanizadora, o la extracción de agua subterránea, tan intensa y agotadora, que ha provocado la declaración de sobreexplotación de dos de las seis unidades hidrogeológicas del Alto Guadiana ${ }^{10}$.

Resulta interesante hacer una mención expresa a la desecación de humedales que tuvo lugar con ocasión de la Ley de 17 de julio de 1956, sobre saneamiento y colonización de los terrenos pantanosos que se extienden a los márgenes de los ríos Guadiana, Cigüela, Záncara y afluentes. Con amparo en la Ley de Colonización de Grandes Zonas de 1939, se consideraban colonizaciones de alto interés las que transformando profundamente las condiciones económicas y sociales de grandes extensiones de terreno exigían para su eje-

${ }^{8}$ Buena cuenta de ello dan DELGADO PIQUERAS y GARRIDO CUENCA en "Política ambiental de Castilla-La Mancha", Observatorio de Politicas Ambientales 2008, Thomson-Aranzadi, Navarra, 2008, pp. 433-435.

\footnotetext{
${ }^{9}$ Es destacable el hecho de que la superficie ocupada por vegetación asociada a ríos, humedales y otros ecosistemas ligados al agua ha sufrido en los últimos años una importante reducción al tiempo que se ha incrementado la superficie forestal arbolada debido a plantaciones forestales destinadas básicamente a fines recreativos.

${ }^{10}$ Una descripción más detallada de los distintas causas que han originado la situación de la Cuenca Alta del Guadiana puede verse en LÓPEZ SANZ, G., La gestión del agua subterránea en la cuenca alta del río Guadiana: de la confrontación a la cooperación, Imprenta Provincial, Ciudad Real, 1998, pp. 17 y ss., y COLETO, C., MARTÍNEZ CORTINA, L, y LLAMAS, R., (ed.), Conflictos entre el desarrollo de las aguas subterráneas y la conservación de los humedales: la cuenca alta del Guadiana, Fundación Marcelino Botín, Ediciones Mundi-Prensa, Madrid, 2002, in totum.
} 
cución obras o trabajos complejos que, superando la capacidad privada, hacían necesario el apoyo técnico, financiero y jurídico del Estado. Entre estas tenían cabida, junto a las marismas, los terrenos pantanosos de gran extensión como los situados en los márgenes del Guadiana y declarados expresamente por la Ley de 1956 como improductivos. De tal forma, se entendía que mediante la ejecución de obras de encauzamiento y desecación estos terrenos yermos serían "rescatados para el cultivo agrícola y destinados a realizar en ellos una labor de colonización, con vista a solucionar un buen número de los problemas agrosociales existentes en las provincias de Ciudad Real, Toledo y Cuenca". A tal fin, se procedió a la delimitación de la zona de saneamiento y colonización por el Consejo de Ministros, se cedió gratuitamente la Instituto Nacional de Colonización la fracción de dicha superficie que era titularidad del Estado, por ser dominio público, y se declaró de utilidad pública la expropiación a favor del citado Organismo de la fracción de la superficie delimitada que permaneciera inculta y fuera de dominio privado. Consecuentemente, se declaró de alto interés nacional las obras y trabajos de saneamiento y colonización de los terrenos pantanosos referidos y que habrían de ser ejecutadas con sujeción al Plan General de Colonización que aprobara el Gobierno.

\section{PRIMERAS ACTUACIONES NORMATIVAS SOBRE LA ZONA DE INFLUENCIA DEL PEAG COMO EXPONENTES DE LA NUE- VA POLÍTICA PÚBLICA MEDIOAMBIENTAL}

Antes incluso de la entrada en vigor de la Ley de Aguas de 1985 la zona del Alto Guadiana, ya fuertemente degrada, fue objeto de las determinantes y decididas actuaciones de los poderes públicos tendentes a iniciar su recuperación física en el marco de un giro copernicano en las políticas públicas sobre espacios naturales. Así, en primer lugar, el Decreto 1874/1973, de 28 de junio, declara Parque Nacional a las Tablas de Daimiel y crea una zona de Reserva Integral de aves acuáticas dentro del mismo. Con tal declaración, al amparo de la otrora vigente Ley de Montes de 1957, se pretendió asegurar, en beneficio de toda la comunidad, la conservación de uno de los ecosistemas más valiosos del territorio nacional y el más representativo de las zonas húmedas de la Mancha, cuya administración y gestión se encomendó al Instituto Nacional para la Conservación de la Naturaleza ${ }^{11}$. Con el fin de alcanzar los fines confesados por la disposición reglamentaria se constituyó el Patronato del Parque Nacional de las Tablas de Daimiel cuyo cometido se centraba en la cooperación a la

${ }^{11}$ Artículos 1 y 4 del Decreto 1874/1973, de 28 de junio. 
conservación y fomento del Parque, además de la redacción del proyecto de reglamentación aplicable al mismo que habría de ser sometido al Ministerio de Agricultura a través del Director del ICONA. Unos años más tarde, la Ley 25/1980, de 3 de mayo, sobre reclasificación del Parque Nacional de las Tablas de Daimiel, se estableció un régimen jurídico especial que abarcaba tanto a las aguas superficiales como a las subterráneas y estaba orientado a proteger el conjunto de los ecosistemas que lo integraban así como a promover la investigación y utilización en orden a la enseñanza y disfrute del Parque Nacional, en razón de su interés educativo, científico, cultural, recreativo, turístico y socioeconómico.

Precisamente esta norma vino a declarar la no aplicación al Parque Nacional de sendas disposiciones de 1918 sobre desecación y saneamiento de lagunas, marismas y terrenos pantanosos y la de 1956 sobre saneamiento y colonización a que se ha hecho referencia anteriormente. El nuevo régimen jurídico diseñando declara zona de protección el Parque Nacional a efectos cinegéticos, donde no se podrá realizar ninguna actividad que no sea de uso agrario y siempre que ésta sea compatible con el mismo. De igual modo, en las zonas de influencia no podrán realizarse actuaciones que puedan modificar o reducir las superficies de las áreas encharcadas o deteriorar la calidad de las aguas, sin el preceptivo informe del Patronato del Parque. En fin, el desarrollo socioeconómico así como la ordenación y uso del parque y las normas sobre gestión y actuaciones de conservación y protección se encomiendan al plan director territorial de coordinación y el plan rector de uso y gestión; este último habría de ser confeccionado por el Ministerio de Agricultura, a través del Instituto Nacional para la Conservación de la Naturaleza ${ }^{12}$.

Tras la Ley 5/2007, de 3 de abril, de la Red de Parques Nacionales, todos aquéllos que hubieran sido declarados antes de su entrada en vigor -lo que tuvo lugar el 5 de abril de 2007- quedaron integrados en la Red de Parques Nacionales ${ }^{13}$, que tenía como finalidad garantizar, como legado para las futuras generaciones, la conservación de una muestra representativa de los principales sis-

12 Véanse los artículos 4 a 7 de la Ley 25/1980, de 3 de mayo, sobre reclasificación del Parque Nacional de las Tablas de Daimiel.

${ }^{13}$ Disposición adicional primera de la Ley 5/2007, de 3 de abril, de la Red de Parques Nacionales. 
temas naturales españoles ${ }^{14}$. A partir de esta norma, la gestión y organización de los Parques Nacionales corresponde directamente a las Comunidades Autónomas en cuyo territorio se encuentran enclavados ${ }^{15}$. En cada uno de éstos, las Administraciones competentes han de elaborar un Plan Rector de Uso y Gestión que se convierte en el instrumento básico de planificación y cuyas determinaciones deben necesariamente ajustarse al Plan Director de la Red de Parques Nacionales, que corresponde realizar a la Administración General del Estado.

Finalmente, la profunda afección sufrida por el Parque Nacional de las Tablas de Daimiel hubo de ser además subvenida, entre otras medidas, por las transferencias de aguas provinentes de la cuenca del Tajo. En efecto, la primera disposición que con carácter temporal y experimental autorizó la derivación de volúmenes de agua de la cuenca alta del Tajo, a través del Acueducto Tajo-Segura, con destino al Parque Nacional de las Tablas de Daimiel fue la Ley 13/1987, de 17 de julio. Tal disposición recordaba que la conservación del Parque Nacional de las Tablas de Daimiel constituía un compromiso ineludible del Estado español derivado tanto de la ley 25/1980, de 3 de mayo como de su inclusión en el convenio sobre humedales de importancia internacional (RAMSAR), de 18 de marzo de 1982. Ciertamente, el futuro del Parque era ya

\footnotetext{
${ }^{14}$ A tal fin, la Red de Parques Nacionales habría de formar un sistema completo y representativo de dichos sistemas naturales; asegurar un marco adecuado para la conservación de los sistemas naturales, basado en la coordinación y cooperación interadministrativa; colaborar en el cumplimiento de los objetivos de los Parques Nacionales, tanto en el ámbito técnico como social o patrimonial; alcanzar sinergias en las acciones promovidas en el marco de la Red por las diferentes Administraciones públicas; cooperar, en el área de influencia socioeconómica de los Parques Nacionales, en la implantación de modelos de desarrollo sostenible que sirvan de referencia para el conjunto del territorio; reforzar la imagen exterior y el papel internacional que desempeñan las políticas españolas en materia de Parques Nacionales, así como las aportaciones de las distintas Administraciones competentes; y, en fin, contribuir a la concienciación ambiental en la sociedad, en colaboración con las instituciones y organizaciones pertinentes (véase el artículo 4 de la Ley que fija los objetivos de la Red de Parques Nacionales).

${ }^{15}$ Salvo la gestión de los Parques Nacionales declarados sobre aguas marinas bajo soberanía o jurisdicción nacional, cuando el ecosistema protegido carezca de continuidad ecológica con la parte terrestre o la zona marítimo-terrestre situadas en la Comunidad Autónoma, que corresponde a la Administración General del Estado. Ahora bien, cuando un Parque Nacional se extiende por el territorio de dos o más Comunidades Autónomas la gestión no se atribuye a ésta sino que se ordena a las Comunidades Autónomas implicadas la búsqueda, de común acuerdo, de las fórmulas de colaboración necesarias para asegurar la aplicación del principio de gestión integrada (artículo 16 de la Ley 5/2007, de la Red de Parques Nacionales).
} 
muy incierto y su degradación creciente, como consecuencia de acciones humanas que habían roto los equilibrios naturales que permitían la existencia del ecosistema tan singular, en concreto, las conocidas cuantiosas y crecientes extracciones de aguas subterráneas en el acuífero de la llanura manchega que provocaron un descenso generalizado y progresivo de los niveles freáticos. Conservar el ecosistema en condiciones similares a las que existían antes de su declaración como Parque Nacional exigía restituir, de alguna manera, las aportaciones hídricas necesarias, lo que tuvo lugar mediante la derivación de caudales de la cuenca alta del Tajo regulada en la Ley que serían vertidos a los cauces de los ríos de la cuenca alta del Guadiana hasta el Parque Nacional (Riansares o Ciguela). La Ley otorgó durante tres años un volumen de agua no superior a $60 \mathrm{hm}^{3}$, sin que la dotación derivada en un año superara los $30 \mathrm{hm}^{3}$ y sin que dicho caudal pudiera ser destinado a usos diferentes de los medioambientales ${ }^{16}$.

Resulta de interés destacar que el artículo 1.4 de la citada Ley disponía que los volúmenes de agua cuya derivación autorizara eran independientes del computo de volúmenes trasvasados regulados por la ley 52/1980, de 16 de octubre, de regulación del régimen económico de la explotación del acueducto Tajo-Segura, lo que fue visto como un nuevo trasvase con cargo a otros recursos excedentarios de la cabecera del Tajo con independencia de los ya comprometidos legalmente hacia el Segura ${ }^{17}$. Dado su carácter temporal la Ley hubo de ser prorrogada en virtud de los Decretos-Leyes 6/1990, de 28 de diciembre y 5/1993, de 16 de abril, que dispusieron la aplicación por sendos períodos de tres años del mismo régimen de derivación de aguas establecido en la Ley $13 / 1987^{18}$.

\footnotetext{
${ }^{16}$ Artículo 1.1. de la Ley 13/1987, de 17 de julio, de derivación de volúmenes de agua de la cuenca alta del tajo, a través del acueducto Tajo-Segura, con carácter experimental, con destino al Parque Nacional de las Tablas de Daimiel.

${ }^{17}$ En este sentido se manifestó CLAVER VALDERAS, J. M., "Situación actual del Trasvase Tajo-Segura", El Derecho de aguas en Iberoamérica y España: cambio y modernización en el inicio del tercer milenio, EMbID IruJo, A., (dir.), Civitas, Madrid, 2002, p. 602.

${ }^{18}$ Durante el período de vigencia de la Ley 13/1987 se autorizaron 41,20 $\mathrm{hm}^{3}$ y al amparo de los Decretos-Leyes se trasvasaron a las Tablas de Daimiel un total de 24,5 y $45 \mathrm{hm}^{3}$ (CLAVER VALDERAS, ibidem, p. 602).

Recientemente, la difícil situación en que se encontraba el Parque, como consecuencia del incendio subterráneo que lo estaba asolando, el Consejo de Ministros aprobó el 6 de noviembre
} 
Posteriormente, la importantísima sequía que azotó el país en los primeros años de la década de los noventa del pasado siglo hizo ver la necesidad de reforzar la potencialidad del acueducto Tajo-Segura como vertebrador territorial del centro y el sudeste de la península, no sólo para superar la situación coyuntural de sequía imperante, sino para paliar parte del problema estructural de desequilibrio hídrico. En este sentido, la Comisión de Infraestructuras y Medio Ambiente del Congreso de los Diputados adoptó una resolución por unanimidad en la que se solicitaba expresamente del Gobierno la presentación de un proyecto de ley para mejorar la explotación del acueducto Tajo-Segura. En su virtud se dictó el Real Decreto-Ley 8/1995, de 4 de agosto, que contenía una serie de medidas con las que se pretendía incrementar el rendimiento de las infraestructuras existentes con su utilización para resolver los graves problemas de abastecimiento urbano y mejorar al mismo tiempo el sistema de aporte al Parque Natural de la Tablas de Daimiel desde el acueducto Tajo-Segura. De este modo, con esta norma se posibilitó el trasvase a La Mancha de hasta $50 \mathrm{hm}^{3}$ anuales creándose además una reserva de hasta $3 \mathrm{hm}^{3}$ por año para atender demandas de abastecimiento menores en las inmediaciones del acueducto Tajo-Segura. Es decir, se autorizó la derivación de recursos hídricos del acueducto Tajo-Segura para el abastecimiento de la cuenta alta del río Guadiana, volumen medio anual derivado que, computado sobre un período máximo de diez años, no podría ser mayor de $50 \mathrm{hm}^{3}$ Dentro de esta cuantía máxima se consideraban incluidas las dotaciones previstas para el Parque Natural de las Tablas de Daimiel en la Ley 13/1987, de 17 de julio, y en los Reales Decretos-leyes 6/1990, de 28 de diciembre, y 5/1993, de 16 de abril, que prorrogaron sus efectos, lo que otorgó a tales dotaciones carácter permanente ${ }^{19}$.

de 2009 una serie de medidas de emergencia para la extinción de la combustión de turba y la restitución de la superficie encharcada en el Parque Nacional de las Tablas de Daimiel. El objetivo de estas medidas es mantener una lamina de agua que permita recuperar el ecosistema del parque. Entre las medidas adoptadas destaca el envío, previo informe favorable de la Comisión Central de Explotación del Acueducto Tajo-Segura, de un trasvase de hasta un máximo de veinte $\mathrm{hm}^{3}$, para lo cual era imprescindible la conclusión de los trabajos de la tubería de la Llanura Manchega y de las obras complementarias necesarias. Las previsiones del Ministerio indicaban que la finalización de los trabajos complementarios necesarios permitiría realizar el citado trasvase en unas condiciones de eficiencia del 90-95 por 100 .

${ }^{19}$ Véase el artículo 1 del Real Decreto-ley 8/1995, de 4 de agosto, por el que se adoptan medidas urgentes de mejora del aprovechamiento del trasvase Tajo-Segura. La opción por la fórmula legal del Real Decreto-Ley no fue del todo compartida por algún sector en la medida en que las obras de conducción del agua desde el acueducto Tajo-Segura hasta su destino para abastecimiento en el Guadiana tardaron varios años en emprenderse. Así, hasta octubre de 2000 


\section{EL PLAN ESPEGIAL DEL ALTO GUADIANA: BREVE REFEREN- CIA A SUS ANTEGEDENTES, CONTENIDO Y PROGRAMAS DE MEDIDAS. CONSIDERAGIÓN ESPEGIAL DE LOS GENTROS DE INTERCAMBIO DE DERECHOS OBJETO DE ESTUDIO}

Para lograr la referida recuperación ambiental del Alto Guadiana las actuaciones previstas en el PEAG se articularon a través de las siguientes medidas: por medio de la ejecución de planes de ordenación de extracciones y de su revisión; por medio de la transformación de derechos sobre aguas privadas en concesiones de aguas públicas; por medio de la adquisición de derechos de uso de agua y de terrenos y, en fin, por medio de la celebración de los contratos de cesión de derechos de uso de agua. Tales medidas son desarrolladas en los artículos 2 y siguientes del Anexo I "Normas", del PEAG. De entre ellas cabe destacar, por su interés para el objeto de este trabajo, la transformación de derechos privados en concesionales como paso previo a la futura y previsible celebración de los contratos de cesión de derechos al uso del agua. De tal forma, como ya permitió el Real Decreto Ley 9/2006, de 15 de septiembre, por el que se adoptan medidas urgentes para paliar los efectos producidos por la sequía en las poblaciones y en las explotaciones agrarias de regadío de determinadas cuencas hidrográfica, los titulares de aprovechamientos de aguas inscritos en el Catálogo de aguas privadas o en la Sección C del Registro de Aguas de la Cuenca podrán solicitar la inscripción en la Sección A de este último, para lo que instarán el otorgamiento de la correspondiente concesión.

Como expresamente indica el artículo 4.3 de las Normas del PEAG, una vez otorgadas las concesiones sus titulares podrán hacer uso del contrato de cesión de derechos de acuerdo con lo dispuesto en el artículo 11 de dichas Normas.

Pero de suma importancia, por constituir el objeto directo del trabajo, es la posible adquisición de derechos de uso del agua y de terrenos prevista en el artículo 5 de las Normas del PEAG. De tal forma, a los efectos de propiciar la

no se publicó la declaración de impacto ambiental del proyecto de "Conducción de agua desde el Acueducto Tajo-Segura para incorporación de recursos a la llanura manchega (Cuenca-Toledo-Ciudad Real), Tramo Conducción principal y Ramal de Gasset" (BOE de 4 de octubre de 2000). En 2001 se publicó la declaración de impacto ambiental correspondiente al Ramal para abastecimiento de agua a Ciudad Real y Puertollano (BOE de 5 de julio de 2001). Estas circunstancias, unidas al retraso hasta febrero del año siguiente de la aprobación de la norma de la derivación de caudales hacia las Tablas de Daimiel para uso medioambiental lleva a CLAVER VALDERAS a enjuiciar la oportunidad del Real Decreto-Ley para articular tales medidas (ob. cit., p. 605 y 606). 
más rápida y eficaz recuperación hídrica de las masas de agua subterránea y la mejora de los ecosistemas a ellas vinculados la Confederación del Guadiana realizará adquisiciones de derechos de propiedad sobre aguas privadas, sobre derechos de aprovechamiento temporal de aguas privadas, sobre concesiones de aguas y sobre terrenos. Debe adelantarse en este punto que las diversas ofertas de adquisición realizadas hasta el momento se han centrado en los derechos de aguas, postergando por el momento la adquisición de terrenos prevista en el PEAG y que tiene como finalidad la recuperación hídrica de la masa de agua subterránea y la mejora de los ecosistemas mediante la forestación de terrenos dedicados al cultivo agrícola.

Así pues, a los efectos de propiciar la más rápida y eficaz recuperación hídrica de las masas de agua subterránea y la mejora de los ecosistemas a ellas vinculadas, y sin perjuicio de la aplicación de otras técnicas de mejor gestión previstas en la legislación de aguas como la revisión concesional, la Confederación del Guadiana podrá llevar a cabo adquisiciones de derechos de propiedad de aguas que tendrán como finalidad en todo caso la consecución de los objetivos del PEAG y se llevarán a cabo a través del Centro de Intercambio de Derechos al Uso del Agua. Como expresamente se establece en el artículo 5 de las Normas del Plan, el Centro podrá destinar los derechos a los siguientes fines:

A) usos ambientales, de forma temporal o definitiva, en tanto perviva la situación de riesgo de la respectiva masa de agua subterránea, entendiéndose por actuaciones medioambientales las que tiendan a la recuperación de los niveles cuantitativos de la masa subterránea y de las masas de agua superficiales a ella asociadas.

B) por razones excepcionales y motivadas, a la cesión a otros usuarios o a la Comunidad Autónoma de Castilla La Mancha ${ }^{20}$. Sin embargo, cabe resaltar que esta segunda opción no ha tenido lugar, habiéndose destinado los caudales adquiridos a través del centro de intercambio exclusivamente a la primera opción.

${ }^{20}$ De acuerdo con el artículo 5.2 de las Normas del PEAG, será el Consorcio el que proponga los criterios de otorgamiento de las concesiones que, en el caso de los usos agrícolas, habrán de ser destinados preferentemente a explotaciones de tipo social. La Confederación del Guadiana otorgará las concesiones tomando en consideración los criterios propuestos por el Consorcio, respetando en todo caso la legislación de aguas, el Plan Hidrológico del Guadiana y este Plan Especial, y atendiendo a las exigencias del interés público. 
Según indican las propias Normas del PEAG, no podrá realizarse ninguna adquisición de derechos que no estén inscritos en el Catálogo de Aguas Privadas o en el Registro de Aguas, en su caso. Ésta se referirá con preferencia a la totalidad de los derechos inscritos en función de lo que técnica y ambientalmente sea justificadamente preferible, siendo la valoración de los mismos la que resulte de un estudio económico que realizará el Consorcio que atenderá, en el caso de las utilizaciones agrícolas, a la relación entre el agua y el valor añadido a la producción agrícola. En todo caso, para la valoración en concreto de los derechos a adquirir, se tendrá en cuenta fundamentalmente el grado de disponibilidad efectiva que tenga el titular en función de lo previsto en los Planes de ordenación de extracciones y de la situación fáctica de su aprovechamiento. En la elaboración del estudio económico, que será público, se dará audiencia a los órganos competentes en materia de agricultura de la Junta de Comunidades de Castilla-La Mancha, y se someterá a informe de las Comunidades de Usuarios.

Una vez realizada la adquisición se procederá a la inscripción o, en su caso, modificación en el Registro de Aguas o en el Catálogo de aguas de la cuenca, según proceda. Igualmente se procederá a la clausura o en su caso modificación de las instalaciones existentes en las condiciones convenidas, como habrá ocasión de comprobar a continuación.

El Consorcio para la Gestión del Plan Especial del Alto Guadiana, pieza angular del mismo, se diseñó en el Protocolo de Colaboración entre la Administración General del Estado y la Junta de Comunidades de Castilla-La Mancha de 23 de octubre de 2007 como el órgano encargado de llevar a cabo las labores de ejecución, coordinación, impulso y seguimiento de las medidas contenidas en las Normas y Programas Sectoriales del PEAG y del Programa de Desarrollo Rural Sostenible del Alto Guadiana. Sus Estatutos fueron finalmente aprobados en virtud de un convenio de colaboración entre las citadas Administraciones, de 25 de febrero de 2008. Entre sus funciones cabe destacar la elaboración y propuesta a la Confederación Hidrográfica del Proyecto de Actuación para la adquisición de derechos y terrenos a que se refiere el artículo 8 de las Normas del PEAG.

Fijado el marco normativo en el que se insertan las distintas ofertas públicas de adquisición de derechos realizadas en la Cuenca del Guadiana se procede a la exposición de las mismas las cuales, con pequeños matices diferenciales, obedecen a las siguientes características. En primer lugar los titulares que podían participar en las operaciones del centro de intercambio serían los concesionarios y titulares de aprovechamientos al uso privativo de las aguas cu- 
yos aprovechamientos destinados a regadío tuvieran sus captaciones o tomas en el perímetro del Acuífero de La Mancha Occidental declarado sobreexplotado por acuerdos de la Junta de Gobierno de la CHG del 4 de febrero de 1987 y 15 de diciembre de 1994 y dentro de la zona declarada sobreexplotada del acuífero del Campo de Montiel, todos ellos situados en la cuenca alta del Guadiana. Además, los titulares habrían de disponer de los caudales efectivos de agua que resultaran suficientes para atender los derechos cuya enajenación se proponía, para lo cual el Organismo de cuenca realizaría las comprobaciones que estimara necesarias. A mayor abundamiento, el pliego de prescripciones técnicas dispone que solamente se adquirirán derechos en aprovechamientos en los que se compruebe que existan caudales efectivos que sean suficientes para atender los citados derechos. Por otra parte, la calidad del agua objeto de cesión debería ser como mínimo la del agua apta para el riego, de acuerdo con las normas contenidas en el Plan Hidrológico I de la cuenca del Guadiana, lo que también sería evaluado por los servicios técnicos de la CHG.

La cesión, y esta es una diferencia importante con las operaciones realizadas por otros centros de intercambio de distintas Cuencas hidrográficas, se realiza en todos los casos con carácter definitivo y por el total destinado a riego que figure en el título acreditativo del aprovechamiento, quedando afectada a la superficie que esté adscrita al mismo. La adquisición se producirá sobre la totalidad de los derechos existentes sobre las aguas destinadas a riego del aprovechamiento de que se trate, incluido el pleno dominio de las mismas en el caso de que no pertenezcan al Dominio público hidráulico.

Hay que destacar la posibilidad de que la adquisición de derechos de aguas se combine con convenios sobre la utilización agroambientalmente adecuada, incluyendo la forestación de los terrenos a los que las aguas estén vinculadas y previa la firma del correspondiente contrato de forestación de las tierras afectadas. En esta hipótesis aún no materializada la superficie mínima que podrá acogerse al programa de forestación será de 5 hectáreas, siendo los trabajos de forestación realizados por la Administración, tanto las fases de plantación o establecimiento como el mantenimiento, recibiendo el propietario una prima compensatoria de $600 € /$ ha durante 20 años a partir del momento de la ejecución de la forestación.

Los importes máximos y mínimos de la compensación económica por la cesión fueron en todos los casos $10.000 €$ y $3.000 €$ para los cultivos no leñosos y $6.000 €$ y $3.000 €$ para los cultivos leñosos. Los criterios de preferencia para la selección de aprovechamientos fueron los siguientes: 1) por razón de la ubicación de la toma la proximidad de las tomas o captaciones a los límites del Par- 
que Nacional de las Tablas de Daimiel y del Parque Natural de las Lagunas de Ruidera, a humedales incluidos en la Red Regional de Áreas Protegidas, a las zonas de policía de los ríos o a captaciones para abastecimiento poblacional, por este orden; 2) por razón económica, menor importe por hectárea de regadío de la compensación solicitada en la oferta de adquisición de los derechos realizada.

Para la evaluación de las ofertas se establecía una puntuación que oscila entre los 25, 15 y 5 puntos, en función de que la distancia del aprovechamiento al Parque Nacional de las Tablas de Daimiel y del Parque Natural de las Lagunas del Ruidera sea menor o igual a 5 kilómetros; mayor de esta distancia y menor o igual que 10 kilómetros; o mayor que esta distancia y menor o igual que 15 kilómetros. En el supuesto de que la distancia del aprovechamiento sea menor o igual a 100 metros del borde del cauce la puntuación correctora es 15 .

La puntuación del precio ofertado por hectárea de regadío de cultivos leñosos se obtiene aplicando la siguiente fórmula: puntuación $=60-(0,01 \times \mathbf{a})$, siendo este valor a el precio ofertado para cultivos leñosos en $€ /$ ha. Si se tiene derecho a regar exclusivamente cultivos no leñosos la puntuación se obtendrá aplicando la siguiente fórmula: puntuación $=(42-0,0042 \times \mathbf{a})$, siendo este valor a el precio ofertado para cultivos no leñosos en $€ /$ ha. Finalmente, si se tiene derecho a regar tanto cultivos leñosos como no leñosos la puntuación se obtendrá aplicando la siguiente fórmula: puntuación $=($ NHL x P1 + NHNL x P2)/(NHL + NHNL), donde P1 es la puntuación obtenida aplicando el criterio del precio ofertado cuando se tiene derecho a regar exclusivamente cultivos leñosos; P2 es la puntuación obtenida aplicando el criterio del precio ofertado cuando se tiene derecho a regar exclusivamente cultivos no leñosos; NHL es el número de hectáreas que se tenga derecho a regar de cultivos leñosos; NHNL es el número de hectáreas que se tenga derecho a regar de cultivos no leñosos. En fin, cuando el título del derecho no distinga entre hectáreas de leñosos y no leñosos, para la determinación de NHL y NHNL se estará a los datos obtenidos en la visita de campo. En cualquier caso, la suma de NHL y NHNL no podrá superar el número total de hectáreas que se tenga derecho a regar.

Como es natural las solicitudes, que tratándose de varios aprovechamientos habrán de ser independientes por cada uno de ellos, deben presentarse junto a una documentación técnica que acredite suficientemente la identidad del titular del aprovechamiento así como las condiciones técnicas y ubicación del mismo. De entre los documentos relacionados en el pliego de condiciones particulares los que han presentado mayor problemática son el certificado del Registro de la Propiedad acreditativo de la titularidad de las fincas en las que se ubique el aprovechamiento objeto de la oferta que no podía tener una anti- 
güedad superior a cinco semanas contadas desde la fecha de presentación de la instancia y la certificación catastral descriptiva y gráfica de las parcelas donde su ubique el aprovechamiento objeto de la oferta. La dificultad de la experiencia del Guadiana derivó de la falta de concordancia entre uno y otro, en unos casos, y, en otros, de la imposibilidad de acreditar por el titular del aprovechamiento el tracto sucesivo registral de la finca a que se destinan los caudales en el Registro de la Propiedad. De tal forma, en la oferta 1/07 de adquisición de derechos, de las 80 proposiciones de venta de derechos 31 fueron rechazadas por no ser titulares registrales de la finca donde se ubicaba el aprovechamiento, por no aportar Certificado del Registro de la Propiedad que acreditara la propiedad de los terrenos, por la falta de acreditación de la superficie total inscrita, por la imposibilidad de comprobar los volúmenes de aguas con derechos ante la ausencia de equipos de bombeo o ante la insuficiencia de caudales efectivos en la extracción. En la oferta 2/07, de las 162 ofertas presentadas fueron admitidas 153, de las cuales 50 (el 29,59\%) fueron rechazadas por causas similares a las anteriormente referidas.

Una vez seleccionadas las solicitudes, y a efectos de realizar las comprobaciones pertinentes, se cruza la documentación presentada con la obrante en los expedientes de la Confederación, pudiéndose requerir a los solicitantes para que realicen la subsanación o mejora de la solicitud si fuera necesario, dando lugar la falta del cumplimiento de este trámite por parte del interesado a la exclusión del procedimiento sin indemnización. De igual modo, a fin de comprobar la situación real, disponibilidad de los caudales y determinar la calidad de las aguas se procede a la correspondiente inspección de los aprovechamientos seleccionados por la CHG. Siendo negativa esta inspección por no cumplir los aprovechamientos los requisitos preceptuados se procede a la exclusión sin contraprestación. Esta inspección no tendrá lugar cuando el aprovechamiento de que se trate ya haya sido objeto de proposición pero no resultara finalmente adjudicataria en anteriores ofertas y se hubiera hecho un reconocimiento sobre el terreno con puesta en funcionamiento de las instalaciones de extracción de aguas y mediara informe favorable para la adquisición de derechos por cumplir los criterios técnicos de la oferta a la que hubiera concurrido.

Las actuaciones a ejecutar por los titulares de los derechos adquiridos una vez formalizada la adquisición han experimentado un notable perfeccionamiento en las recientes ofertas tratando decididamente de evitar los fraudes y actuaciones ilegales posteriores a la celebración del contrato. En tal sentido, en la primera oferta pública, la 1/06, solo se exigía la retirada de equipos e instalaciones, el precintado o clausura de las captaciones del aprovechamiento de que se tratara de forma que se impidiera su utilización así como la instalación, 
en su caso, de dispositivos de medida para el control de los caudales y volúmenes correspondientes de los usos de agua que quedaran subsistentes. En la oferta $1 / 08$, con más cautela (al menos sobre el papel), se imponen mayores requerimientos que podrán impedir el uso del aprovechamiento al exigirse ahora más actuaciones que el simple precintado de los pozos o aprovechamientos. En efecto, una vez formalizada la adquisición de los derechos, los anteriores titulares deben en el plazo de un mes proceder a retirar los equipos de bombeo, extracción, impulsión de agua y, en general, cualquier dispositivo tanto sumergido como en superficie, destinado a la extracción del agua del subsuelo como a su puesta a disposición en superficie tales como bomba, tubería de impulsión, cableado eléctrico y metálico de sustentación, centradores, ejes verticales de rotación, etc, de tal modo que en el interior del pozo no quede más que el entubado del mismo, si existiere. También es preciso realizar el rellenado del interior del pozo con áridos desde el fondo del mismo hasta una profundidad mínima de dos metros contados desde la superficie del terreno*.

En el caso de que subsistan usos del agua distintos de los adquiridos los titulares habrán de instalar en el plazo mencionado supra los dispositivos de medida que permitan el control de los caudales y volúmenes correspondientes. Como puede apreciarse, el cumplimiento de tales medidas de seguridad podrá evitar el uso fraudulento de los caudales por los antiguos titulares después de su adquisición por la $\mathrm{CHG}$, lo que ha venido siendo una práctica reiterada en muchas cuencas de la que no escapa la del Guadiana.

\footnotetext{
* Resulta interesante exponer el procedimiento de relleno de los pozos a efectos prácticos para otras experiencias pues éste se efectuará mediante tolva o similar con arena o gravilla silícea limpia y seleccionada con granulometría mínima de $0,5 \mathrm{~mm}$ y máxima de $10 \mathrm{~mm}$ de diámetro. Para el cálculo del volumen de inyección se deberá tener en cuenta la profundidad total del pozo y el diámetro del mismo. El sellado será realizado por personal técnico cualificado y con maquinaria adecuada, controlando los volúmenes de grava añadidos y las profundidades del nivel freático. El material de sellado se adicionará paulatinamente y, si es necesario, por fases, permitiendo las estabilizaciones del nivel del agua subterránea necesarias, de tal modo que se evite el rebose de agua por la boca del pozo y la subsiguiente inundación de la zona de trabajo. De ser necesario se permitirá la consolidación y estabilización del material de sellado mediante la espera del tiempo necesario. Los dos metros de profundidad hasta la superficie será rellenado por un tapón de cemento líquido Pórtland y arena (mortero) descargado desde la superficie, prestando especial atención a la inyección de cemento para que éste penetre lo suficiente a través de los poros del material de sellado infrayacente, así como en el entorno próximo del pozo, en su caso. Si el entubado sobresale de la superficie del terreno se rellenará dicho volumen con mortero, en caso contrario se construirá una caja de cemente de al menos $10 \mathrm{~cm}$ de altura que permita la localización posterior de la ubicación del pozo sellado.
} 
En fin, una vez formalizada la adquisición de los derechos, la CHG procederá a realizar las anotaciones correspondientes en el Registro de Aguas o en el Catálogo de Aguas privadas, según proceda, inscribiendo dichos derechos a su nombre. También realizará, en su caso, las actuaciones oportunas tendentes a lograr la inscripción a su nombre en el Registro de la Propiedad de esos derechos. Igualmente, la Confederación podrá realizar las actuaciones oportunas ante el Catastro Inmobiliario para que las tierras en las que antes de la adquisición por la CHG de los derechos podía realizarse riego en base a los mismos, sean consideradas o calificadas de secano. Extremos todos ellos de suma importancia por la actualización de los Registros y Catálogos que conlleva.

En los informes de valoración de las dos ofertas públicas de adquisición de derechos realizadas en 2007 la Confederación Hidrográfica del Guadiana presenta como oferta tipo para los cultivos leñosos de la oferta $1 / 07$ una finca de 11,7 Has y $5.764 €$ de oferta media y para los cultivos no leñosos una finca media de 33 Has y $9.669 €$ de oferta media. En la oferta 2/07 se presenta como oferta tipo para los cultivos leñosos una finca de 7,13 Has y $5.883,5 €$ y para los cultivos no leñosos una finca media de 16,64 Has y 9.789,91€ de oferta media. La oferta 1/08 ha contado con mayor número de solicitudes, 268, de las que 81 fueron excluidas en la Mesa de Contratación de Apertura de ofertas económicas; 70 fueron excluidas por informes desfavorables; 4 renunciaron los interesados y 113 recibieron informe favorable. El presupuesto final de adquisición fue de 11.945.342,60€.

A lo largo del año 2009 han tenido lugar dos nuevas ofertas públicas de adquisición de derechos en similares términos a los del año 2008. La primera aprobada por Resolución de la Confederación de 9 de marzo y por importe de $20.000 €$, y la segunda, de 29 de septiembre, aún en licitación cuando se escriben estas líneas, por importe de $11.950 .000 €$.

\section{G) GONFEDERAGIÓN HIDROGRÁFICA DEL JÚGAR}

En la Confederación del Júcar se han venido produciendo diversas ofertas públicas de adquisición de derechos desde el año 2006. La primera convocatoria fue acordada por Resolución de la Presidencia de 27 de diciembre de $2006^{21}$. Todas ellas tenían por objeto la adquisición de derechos en el tramo medio de la cuenca del río Júcar (entre los embalses de Alarcón y Molinar y acuífero Mioceno de la Unidad Hidrogeológica de la Mancha Oriental), don-

${ }^{21}$ Esta primera convocatoria hubo de prorrogarse por falta de presentación de solicitudes en virtud de Anuncio de la Confederación publicado en el BOE de 15 de marzo de 2007. 
de la reducción de las extracciones en las zonas más próximas al río de esta unidad hidrogeológica permitiría un incremento de los aportes del acuífero al río y una consecuente mejora ambiental del mismo. La especial situación hidrológica ha venido obligando a la Junta Central de Regantes de la Mancha Oriental a acordar reducciones del uso del agua para las campañas de riego, de tal forma en 2007 la dotación máxima disponible por cada usuario fue del $80 \%$ de lo establecido para cada uno de forma individualizada ${ }^{22}$. Sobre esta reducción la oferta pública tenía como finalidad lograr una reducción adicional del 40\% como mínimo, con fines ambientales tanto en las captaciones superficiales como en las subterráneas. Finalmente, el volumen ofertable tras aplicar tales reducciones sería como mínimo del $70 \%$, salvo los concesionarios de las tomas superficiales del tramo comprendido entre el embalse de Alarcón y Molinar que debían ofertar la totalidad del remanente ${ }^{23}$.

$\mathrm{Al}$ igual que en otras confederaciones, entre los requisitos específicos de los interesados era imprescindible no solo disponer de los caudales efectivos suficientes para atender los derechos que se enajenarían sino también una utilización efectiva del aprovechamiento al menos en dos de las campañas de 2003-2004 a 2005-2006.

Las posteriores ofertas de 2008 presentan particularidades destacables y así, además de que los volúmenes ofertables, tras las reducciones que de forma similar a la anterior convocatoria rondaban el $40 \%$, tampoco alcanzaron el $100 \%$ al fijarse en el 70\% y 85\% del remanente. Ahora bien, las superficies a las que se aplicarían las correspondientes dotaciones sería exclusivamente las que hubieran sido reconocidas por la Confederación en el correspondiente expediente de regularización administrativa que trae causa del artículo 24 del Plan Hidrológico del Júcar ${ }^{24}$.

${ }^{22}$ Acuerdo de la Asamblea de la Junta Central de Regantes de la Mancha Oriental de 4 de noviembre de 2006.

${ }^{23}$ En el supuesto de que estos titulares quisieran reservarse caudales y no ofertar todo el remante debían identificar las parcelas a que destinarían los caudales, el tipo de cultivo y el volumen de agua reservado para dicho uso, sometiéndose el cumplimiento de dicha reserva a un control de acuerdo con las normas del Plan de Explotación acordado por la Junta Central de Regantes de la Mancha Oriental.

${ }^{24}$ En su virtud, entre otras determinaciones se obligaba a la conclusión de la inscripción de los usos de aguas subterráneas del Acuífero de la Mancha Oriental, al otorgamiento de la correspondiente concesión de las superficies de regadío transformadas después de 1986 y se imponía la integración de todos los usuarios en el ámbito del acuífero en una única comunidad de usuarios. En cumplimiento de lo anterior, la Presidencia de este Organismo dictó la Resolución de 19 de febrero de 1999, que entre otros contenidos, acordó reconocer y declarar a la Junta 
En las ofertas más recientes se obligó a los concurrentes a reservar un volumen en la totalidad del año hidrológico 2007/2008 de 2.000 metros cúbicos por hectárea que habría de ser aplicado a los cultivos de primavera y, en cualquier caso, antes del 30 de junio. De esta obligación solo se excluyó las explotaciones cuyas tomas subterráneas se encontraran dentro del perímetro de la oferta pública, quienes podrían realizar el riego después de la citada fecha en una cuantía máxima del $50 \%$ y siempre que se destinaran a cultivos hortícolas implantados antes del 14 de marzo de 2008.

\section{D) CONFEDERAGIÓN HIDROGRÁFICA DEL GUADALQUIVIR}

El marco jurídico del que ha de partirse en la Confederación Hidrográfica del Guadalquivir es el Real Decreto 1666/2008, de 17 de octubre, sobre traspaso de funciones y servicios de la Administración del Estado a la Comunidad Autónoma de Andalucía en materia de recursos y aprovechamientos hidráulicos correspondientes a las aguas de la cuenca del Guadalquivir que discurren íntegramente por el territorio de la comunidad autónoma. Esta disposición trae causa particularmente del artículo 51 de la Ley Orgánica 2/2007, de 19 de marzo, por la que se aprueba el Estatuto de Autonomía de Andalucía. En virtud de este artículo, de dudosa constitucionalidad, aquélla Comunidad ostenta competencias exclusivas sobre las aguas de la cuenca del Guadal-

Central de Regantes de la Mancha Oriental como la única comunidad de usuarios válidamente constituida de conformidad con el artículo 24.4.e del Plan Hidrológico del Júcar y ordenar la integración inmediata en la Junta Central de Regantes de la Mancha Oriental de todos los usuarios de aguas subterráneas cuyos aprovechamientos radiquen en el ámbito territorial de la Unidad Hidrogeológica 08.29 Mancha Oriental. Posteriormente, dada la constatada interrelación entre las aguas superficiales y subterráneas en al Unidad Hidrogeológica de la Mancha Oriental, por Resolución del Presidente de la Confederación de 24 de noviembre de 2008 se acordó la integración en la Junta Central de todos los usuarios de aguas superficiales de los tramos de ríos incluidos en dicha Unidad.

Entre tanto finalice el proceso de regularización administrativa de aprovechamientos en la Mancha Oriental para cada campaña de riego se viene autorizando para cada uno de los usuarios de agua subterráneas con destino a regadío, de forma individualizada, el volumen disponible minorado por las posibles reducciones que legalmente pudieran ser aprobadas, sin que pueda tener lugar el riego de las superficies que no estén contenidas en dichos expedientes de regularización. Por su parte, los consumos de aguas superficiales deben constar en los correspondientes planes de explotación que se han de presentar ante la Junta Central de Regantes de la Mancha Oriental para obtener el correspondiente visado (estos sirven de títulos acreditativos del riego efectivo en las campañas de riego de los últimos cinco años exigidas en las ofertas públicas de adquisición de derechos). 
quivir que transcurren por su territorio y no afectan a otra Comunidad Autónoma, sin perjuicio de la planificación general del ciclo hidrológico, de las normas básicas sobre protección del medio ambiente, de las obras públicas hidráulicas de interés general y de lo previsto en el artículo 149.1.22. ${ }^{a}$ de la Constitución. Como puede comprobarse, el texto andaluz somete a un conjunto de "precauciones" la atribución de las competencias y así, la competencia sobre la parte andaluza de la cuenca del Guadalquivir es exclusiva siempre y cuando las aguas no afecten a otra comunidad y sin perjuicio de la planificación general del ciclo hidrológico, de las normas básicas sobre protección del medio ambiente, de las obras hidráulicas de interés general "y de lo previsto en el artículo 149.1.22 CE”. Con todo ello, el Estado seguiría gestionando las aguas de la cuenca del Guadalquivir que discurren por más de una CA y que afecten a CCAA distintas de la andaluza, mientras que la CA andaluza gestionaría las que discurren por más de una CA pero no afectan a otras Comunidades de la cuenca ${ }^{25}$.

Volviendo al objeto de nuestro estudio puede comprobarse que en el Anexo D, número 8 del citado Real Decreto 1666/2008, la creación de los centros de intercambio se ha configurado como una competencia compartida entre las Administraciones estatal y autonómica, toda vez que constituye una de las funciones en que concurriendo ambas los crean conjuntamente ${ }^{26}$.

En este punto ha de indicarse que pese al Acuerdo del Consejo de Ministros de 4 de abril de 2008, por el que se autoriza la constitución de un centro de intercambio en la cuenca del Guadalquivir para acometer una explotación más racional de los recursos hídricos obteniendo una mayor disponibilidad de

${ }^{25}$ Como advierte EMBID IRUJO, ésta es una disquisición casi de corte escolástico en la que lo primero es imprescindible creer que esas aguas existen y que se pueden delimitar claramente en la práctica. La delimitación señalada solo podría realizarse con el presupuesto previo de una planificación hidrológica que hubiera señalado cuáles son esas aguas del Guadalquivir que discurren por más de una CA pero que al no afectar a otras CA son susceptibles de cesión a la andaluza sin lesión constitucional. En tal caso, habría que diferir la efectividad del precepto hasta que se hubiera aprobado tal planificación hidrológica (EMBID Irujo, A., El Derecho de Aguas en Brasil y España, Aranzadi, Navarra, 2008, pp. 43 y ss).

${ }^{26}$ Por el contrario, se traspasa a la Administración autonómica la competencia para autorizar los contratos de cesión de derechos al uso de las aguas del Guadalquivir que transcurren por el territorio de Andalucía y que no afecten a otra comunidad. Delimitación que, como se ha señalado, desde luego resultará difícil de efectuar y que ha de ser previa al ejercicio de esta competencia. 
los mismos - al tiempo de introducir nuevas formas de gestión del agua y una amplia concienciación de la sociedad en relación con las necesidades reales de agua y la mejor utilización de las misma-, esta figura no ha sido puesta en funcionamiento en esta cuenca. Por el contrario, sí han tenido mayor repercusión los contratos de cesión de derechos entre particulares (especialmente regantes), habiéndose celebrados un número importante de ellos, aunque esta cuestión escapa al objeto de este estudio.

Finalmente es preciso hacer referencia a la recientemente publicada Ley 9/2010, de 30 de junio, de Aguas de la Comunidad Autónoma de Andalucía ${ }^{27}$ en la que se regula de forma particular, y a veces a mi juicio contraviniendo de la legislación estatal, la constitución de bancos públicos del agua. Prima facie, resulta llamativo el que el articulo 46 del citado Anteproyecto atribuya la competencia para su constitución solo a la Comunidad Autónoma - en virtud de Decreto del Consejo de Gobierno en el que se acuerde su constitución y se establezca el régimen de las ofertas que se puedan realizar por la Agencia Andaluza del Agua ${ }^{28}$ - sin establecer mecanismos de coordinación con la Administración estatal cuando, según hemos visto, ésta es una función en la que han de concurrir ambas Administraciones, según el citado Real Decreto 1666/2008, de traspaso de competencias. De tal forma, en cada demarcación o, en su caso, distrito hidrográfico de Andalucía, podrá constituirse un banco público del agua, a través del cual la Agencia Andaluza del Agua podrá realizar ofertas públicas de adquisición de derechos de uso del agua, para conseguir, por este orden de preferencia, el buen estado ecológico de las masas de agua; corregir los desequilibrios de recursos en los sistemas de explotación; constituir reservas para los fines previstos en los planes hidrológicos de demarcación; atender fines concretos de interés autonómico; o ceder los derechos de uso del agua por el precio acordado, en cuyo caso se estará a lo dispuesto por la normativa básica para los centros de intercambio de derechos. Las dotaciones del banco provendrán de los derechos que la Administración haya obtenido a través de expropiaciones, revisión o extinción de derechos concesionales.

Finalmente, resulta altamente llamativo la alteración por esta norma autonómica de uno de los requisitos subjetivos exigidos por la normativa estatal de aguas al permitir la adquisición de derechos de agua en estos bancos a quienes

${ }^{27}$ Publicado en el Boletín Oficial del Estado el 27 de agosto de 2010.

${ }^{28} \mathrm{Y}$ sin perjuicio de lo establecido en la normativa básica para los centros de intercambio de derechos, según reza el artículo 47.6 de la L. 9/2010, de 30 de julio. 
no sean usuarios. En efecto, el artículo 46.7 de la Ley andaluza establece que para adquirir derechos por este mecanismo no se requerirá la condición previa de usuario, cuando los artículos 71 del TRLA y, especialmente, el artículo 354.2 del $\mathrm{RDPH}$ no dejan duda al respecto, reconociendo exclusivamente este derecho a los concesionarios y titulares de derechos al uso privativo de las aguas.

\section{FINAL}

En la conclusión del presente trabajo es conveniente hacer una valoración total de las experiencias expuestas de los bancos del agua, para lo cual conviene visualizarlos con cierta perspectiva. No ha de ignorarse que, al menos para quien escribe estas líneas, los centos de intercambio creeaban una cierta expectativa por representar un alternativa que, junto con el contrato de cesión y del resto de instrumentos de gestión de los recursos hídricos, podía ayudar a afrontar la delicada situación hídrica que venía atrasando nuestro país (y que parece haber dado una tragua en el último hidrológico). La realidad ha sido sensiblemente distinta a la proyectada (o imaginada), pues se ha podido comprobar cómo la virtualidad de los centros de intercambio ha sido menor de la esperada. Así, el volumen de recursos reasignados a través de est institución, ha sido, en unos casos ínfimos (menos del 1\% del total de los recursos de la cuenca, en la del Segura), hasta el punto de hacer peligrar la convocatoria de futuras ofertas no gozaban de la confianza de los regantes, lo que provocó que en diversas ocasiones las OPAD quedarán desiertas y hubieran de repetirse en diversas ocasiones así como ampliarse los plazos de presentación de solicitudes; o, en fin, en otros supuestos, los centros de intercambio han sido prácticamente nulos, no habiéndose realizado ofertas, como en el caso de la Cuecia del Guadalquivir.

Solamente en la experiencia del Guadiana puede decise que ha tenido una cierta virtualidad o existencia práctica aunque, por qué no decirlo, de una forma sensiblemente distinta a la configuración teórica que recibió esta institución. En efecto, al producirse en esta Cuencia las adquisiciones de derechos de forma definitiva, no temporal, en innegable que más que una redistribución de recursos lo que ha producido son auténticos rescates de los derechos concesionales. Ciertamente, la delicada situación ambiental del Alto Guadiana y el espíritu que insufla las actuaciones de los Poderes Públicos en este ámbito parece justificar tal forma de proceder.

En fin, el desarrrollo práctico de las instituciones jurídicas en no pocas ocasiones discurre por diversos derroteros de los que la teoría puede disponer, y los bancos del agua no han escapado a esta realidad. 